Revista PSICOLOGIA, 2020, Vol. 34 (1), 43-55. doi: 10.17575/psicologia.v34i1.1469

\title{
Impacto da redução de recompensas no comportamento dos colaboradores: E quando o trabalho é um chamamento?
}

\author{
Liliana Pitacho ${ }^{1}$, Patricia Jardim da Palma ${ }^{1} \&$ Pedro Correia ${ }^{1}$ \\ 1 Centre for Public Administration \& Public Policies; School of Social and Political Sciences, University of \\ Lisbon, Portugal
}

\begin{abstract}
Resumo: No cenário global de severa crise económica e financeira, governos e empresas enfrentam um período de grande austeridade o que os conduziu como nunca a elevados cortes dos custos de trabalho, com destaque para o corte e redução das recompensas dos colaboradores. Este artigo apresenta, então, um modelo concetual que teoriza acerca da orientação para o trabalho (Emprego, Carreira e Chamamento) enquanto variável moderadora da relação entre o corte ou redução das recompensas e o comportamento dos colaboradores, nomeadamente, no que ao desempenho e intenção de saída diz respeito. Este modelo acarreta tanto implicações teóricas como práticas, quer para a compreensão do comportamento organizacional, quer para as práticas de gestão de recursos humanos, especialmente, para a gestão das recompensas.
\end{abstract}

Palavras-chave: Recompensas; crise económica; orientação para o trabalho; intenção de saída; desempenho.

Impact of rewards reduction on employees' behaviour: And when the work is a calling? In the global context of severe economic and financial crisis, governments and companies face a period of great austerity which has led them, as never before, to high cuts in labour costs, especially the cutbacks and reduction of rewards. This paper explores a conceptual model that presentation of work orientation (job, career and calling) as a moderating variable in the relationship between the reduction or cuts of rewards and the employees' behaviours, highlighting performance and turnover intentions. This conceptual model has both theoretical and practical implications for both the understanding of organizational behaviour and for human resources practices, especially for the rewards' management.

Keywords: Rewards; economic crisis; work orientation; turnover intent; performance.

As políticas e práticas de gestão de compensação são extremamente valorizadas e críticas para o sucesso das organizações na medida em que têm um elevado impacto ao nível do comportamento dos colaboradores, do seu desempenho e da sua intenção de saída e consequentemente, um impacto direto na performance financeira da organização (Huselid, 1995).

As recompensas atribuídas a cada colaborador comportam em si importantes valores simbólicos e emocionais fortemente associados à autoestima e ao status social, o que vai muito para além do seu valor económico e instrumental (Hakonen, Maaniemi \& Hakanen, 2011). De acordo com Vroom (1964) não são só as recompensas em si que influenciam o comportamento e atitude dos colaboradores, a forma satisfatória ou não com que cada individuo as interpreta tem tanto ou mais impacto dos que as recompensas por si. Além disso, o significado do pagamento (conjunto de recompensas) difere de individuo para individuo e, é através do significado que lhe é atribuído que este influencia os colaboradores, logo, quanto maior a importância atribuída ao pagamento maior o seu impacto.

Contudo, e apesar da reconhecida importância das recompensas para a motivação e retenção dos colaboradores (Rynes, Gerhart \& Minette, 2004), após o mundo ter imergido em 2007 numa profunda crise económica e financeira que representa a maior recessão de sempre da era pós-guerra (Elsby, Hobijn \& Sahin, 2010), designada na literatura por Grande Recessão (Carneiro, Portugal \& Varejão, 2014), as empresas viram-se obrigadas a grandes reajustes por forma a garantir a sua sobrevivência. Para o efeito, uma das estratégias utilizadas pelas empresas prendeu-se com o corte de custos de trabalho. Destaca-se destes cortes a redução do número de colaboradores, o congelamento dos salários base, a redução ou extinção de bónus e outros benefícios monetários e não monetários, como por exemplo o congelamento de promoções (Fabiani et al., 2015).

\footnotetext{
${ }^{1}$ Morada para correspondência: Liliana Pitacho, Centre for Public Administration \& Public Policies, School of Social and Political Sciences, University of Lisbon, Portugal, Rua Almerindo Lessa, 1300-663 Lisboa, Portugal. E-mail: lpitacho@iscsp.ulisboa.com. This work was supported by University of Lisbon.
} 
A execução desta estratégia de redução pelas entidades empregadoras tem como intuito fazer face ao contexto económico adverso, contudo, a escassa literatura sobre cortes salariais refere que estes acarretam consequências negativas para a moral e satisfação dos colaboradores, refletindo-se numa diminuição acentuada do seu desempenho e num aumento da intenção de saída dos mesmos (Bewley, 1998). Apesar disso, e do dinheiro desempenhar um papel relevante na vida de qualquer individuo, Wrzesniewski e colaboradores (1997) concluíram que existem diferentes orientações de trabalho, ou seja, nem todas as pessoas atribuem o mesmo significado psicológico ao trabalho, pelo que nem todos os indivíduos procuram retirar do trabalho os mesmos objetivos. Ou seja, nem todas as pessoas trabalham exclusivamente, ou primariamente, por motivações económicas. Partindo desta diferenciação, os autores, conceptualizaram a existência de três estilos ou tipos distintos de orientação para o trabalho: Emprego, Carreira e Chamamento. Sendo apenas os primeiros movidos exclusivamente por motivações financeiras (Wresniewski et al., 1997).

Posto isto, o presente ensaio teórico visa apresentar um modelo concetual que recorre à orientação para o trabalho enquanto variável explicativa dos distintos comportamentos dos colaboradores em momentos de cortes de recompensas. Ou seja, o presente modelo assume a orientação para o trabalho como uma variável moderadora da relação entre o corte de recompensas e o comportamento dos colaboradores. Preconizando, então, que mediante o estilo de orientação para o trabalho de cada colaborador, estes irão reagir de forma diferenciada perante situações de corte ou redução de recompensas.

0 modelo torna-se relevante pelas implicações teóricas e práticas que acarreta. A nível teórico contribui de forma inequívoca tanto para a literatura das recompensas na medida em que propõe um novo fator moderador do seu impacto no comportamento dos colaboradores, bem como para literatura da orientação para o trabalho e, abre, ainda, portas a reflexão sobre as implicações da rigidez salarial imposta quer por legislação quer por forças sindicais ou trabalhistas. No que respeita às implicações para a praxis organizacional aponta para a necessidade de se conceber sistemas de recompensas, que sem deixarem de atender às teorias da justiça e equidade, tenham a linha de conta as diferenças individuais e as preferências subjacentes à orientação para o trabalho. E, produz ainda informação relevante para a gestão de recursos humanos em momentos de crise ou instabilidade económica e financeira.

\section{Recompensas e comportamento dos colaboradores}

As recompensas são encaradas como elemento chave da gestão estratégica de qualquer organização e, têm como principal intuito o alinhamento entre os objetivos da organização e os objetivos do colaborador, bem como estimular a atração e retenção de colaboradores, promovendo, igualmente, a motivação para o desempenho (Jiang et al., 2009). Mas, contribui também para dissuadir comportamentos menos desejáveis, como a saída voluntariados colaboradores e o absentismo (De Gieter \& Hofmans, 2015). Ou seja, de acordo com Rynes e colaboradores (2004) as recompensas são utilizadas como ferramentas para gerir e guiar o comportamento dos colaboradores, sendo a sua eficácia mensurável através de importantes índices de insatisfação com o trabalho, sendo eles o absentismo, a baixo desempenho e, a intenção de saída voluntária.

No que concerne à intenção de saída, esta tem sido definida por Tett e Meyer (1993) como a vontade consciente e deliberada de deixar a organização e, consiste numa questão relevante tanto a nível prático como teórico. Uma parte significativa dos estudos que abordam a intenção de saída voluntária centram-se especialmente nos seus antecedentes (Chang, Wang \& Huang, 2013), facto que se prende sobretudo com as suas implicações práticas, nomeadamente, com o conhecimento sobre os fatores que motivam a saída voluntária dos colaboradores, permitindo às administrações das organizações controlar esses fatores, quando ao seu alcance, de forma a evitar a saída disfuncional, ou seja, a saída de colaboradores chave para a organização (Chang et al., 2013). De modo sucinto, a rotatividade dos colaboradores deve-se sobretudo a dois fatores essenciais, à perceção da facilidade de movimento, que se refere inequivocamente a uma análise das alternativas e oportunidades e à conveniência do movimento fortemente influenciado pela satisfação e motivação (Abdullah et al., 2012). A saída voluntária dos colaboradores tem sido uma das principais preocupações quer de investigadores quer de gestores principalmente devido aos seus elevados custos para a organização, mas também devido ao seu impacto no desempenho financeiro das mesmas (Dhanpat, Modau, Lugisani, Mabojane \& Phiri, 2018; Schmidt, Willness, Jones \& Bourdage, 2018).

Por sua vez, no que respeita ao desempenho humano são diversos os autores que procuram explicar o desempenho individual. Os modelos iniciais apresentavam este desempenho como função da motivação e das competências (eg.: Kanfer \& Ackerman, 1989).Contudo, e apesar de não descurarem estes fatores os modelos mais recentes demonstram a complexidade do fenómeno apresentando-o como função de fatores pessoais e organizacionais, como por exemplo, a estabilidade emocional, as características de personalidade, o comprometimento organizacional, o bem-estar, práticas de recursos humanos, características do trabalho e clima organizacional entre outros (eg.: Guest, 2017; Kaya \& Baskaya, 2016; Peiró, Bayona, Caballer \& Fabio, 2020; Wang, Jiang, Weng \& Wang, 2019). Além disso, diferentes 
perspetivas teóricas apontam para a utilidade dos incentivos financeiros na ativação e sustentabilidade da motivação para o desempenho, verificando-se, contudo, que apesar da relação existente, o impacto da componente financeira no comportamento dos colaboradores é inconsistente, quer no que respeita a atração, como na retenção e na motivação dos colaboradores para o desempenho (Cao, Chen \& Song, 2013). Principalmente por este facto, os incentivos financeiros e, o seu uso, tem sido o foco de diversos investigadores e profissionais dedicados à maximização do desempenho humano (Condly, Clark \& Stolovitch, 2003).

É sobretudo devido a estas inconsistências e ao facto dos modelos tradicionais de recompensas se terem demonstrado insuficientes no que respeita a sua efetividade de atração, retenção e motivação dos colaboradores que estes têm sofrido uma forte evolução afastando-se dos modelos tradicionais enraizados nas teorias económicas supracitadas (Cao et al., 2013). Assim, os novos modelos vão cada vez mais ao encontro das teorias psicológicas sobre a motivação e a satisfação (e.g.: Herzberg, 1959) que explicitam a importância de se recorrer a tipos de recompensas alternativas. Para Watson e Singh (2005), por exemplo, é preciso mais que dinheiro para envolver e reter uma força de trabalho de elevada qualidade e, como tal quer estudiosos, quer gestores, têm recorrido cada vez mais, ao sistema de recompensas total. Estes sistemas reconhecem a importância das recompensas financeiras, mas salientam a necessidade de integrar outro tipo de recompensas não materiais (Armstrong, 2010). Posto isto, fica claro que o termo pagamento refere-se a todos os tipos de recompensas, não só monetárias, mas também não monetárias, psicológicas e, ainda ao processo pelo qual o sistema de compensação é administrado (Williams et al., 2008).

O pagamento total ou sistema de recompensas total inclui não apenas o salário ou os benefícios monetários, mas também incentivos não materiais, logo, independentemente da abordagem é patente a existência de 2 tipos de recompensas, as intrínsecas e as extrínsecas (Cao et al., 2013).

A temática das políticas e práticas de compensação é extremamente valorizada sobretudo devido ao seu impacto ao nível do comportamento dos colaboradores, nomeadamente do desempenho e intenção de saída e consequentemente o seu impacto para a performance financeira das empresas (Huselid, 1995). Contudo, a Grande Recessão atirou as empresas para a luta da sobrevivência obrigando a medidas de corte nunca antes tomadas sobretudo ao nível do corte de recompensas (Fabiani et al., 2015). Estes cortes de recompensas levados a cabo pelas organizações, sejam do setor privado ou público, não se resume exclusivamente ao salário base de cada colaborador, mas também ao corte de bónus e benefícios, quer sejam eles financeiros ou não (Babecky et al., 2009).

A Grande recessão começou por levar os próprios governos a realizar cortes no que ao trabalho diz respeito, assim, de acordo com o Benchmarking Working Europe (2014) emitido pelo Sindicato Europeu (Syndicate European Trade Union), entre os anos de 2008 e 2013, dezassete dos vinte sete países realizam congelamentos salariais no setor público, enquanto oito governos realizaram cortes superiores a $10 \%$ no salário dos seus funcionários públicos, com destaque para Espanha, Irlanda, Itália e Portugal que o realizaram por recomendação do Fundo Monetário Internacional. O Sindicato Europeu (2014) afirmou ainda que cinco países (Grécia, Letónia, Hungria, Roménia e Lituânia) realizaram cortes salariais entre os $15 \%$ e os $30 \%$ e, além disso em sete países (Grécia, Hungria, Portugal, Espanha, Roménia, Dinamarca e Estónia) foram extintos bónus e benefícios especiais. No caso Português, por exemplo, o tribunal Constitucional declarou que os cortes levados a cabo pelo governo eram inconstitucionais, contudo, o Estado Português manteve-se irrevogável na sua decisão.

Mas não foram só os Governos Estatais que se viram obrigados a medidas extremas para fazer face à austeridade imposta, num dos primeiros estudos realizados sobre o ajustamento empresarial à crise económica e financeira que contou com a participação de nove países (e.g.: Áustria, Bélgica, Republica Checa, Estónia, França, Itália, Holanda, Polónia e Espanha), o Banco Central Europeu verificou que os gestores se mantinham resistentes aos cortes salariais. Contudo, e apesar de o tentarem evitar, ainda durante o ano de 2009, início do processo de ajustamento, 1.2\% das empresas admitiram ter realizado cortes no salário base dos seus colaboradores, mas ainda mais relevante, 9.8\% das empresas admitiram ter levado a cabo cortes nas componentes flexíveis do pagamento dos seus colaboradores (Fabiani et al., 2015).

Contudo, estes dados remontam a 2009, início do ajustamento das empresas à grande recessão, além disso, a lista de países, apesar de bem composta, exclui, Irlanda, Grécia e Portugal, 3 países fortemente afetados pela crise mundial e onde foram impostas fortes medidas de austeridade (Carneiro et al., 2014).

Olhando para dados mais recentes, o Banco de Portugal (Martins, 2016) emitiu um relatório que nos permite visualizar o comportamento das empresas entre o anos 2010 e 2013, período de crise mais severa, tendo-se verificado que apesar das forças e pressões sindicais e de uma legislação laboral rígida no que à flexibilidade salarial diz respeito muitas foram as empresas que se viram obrigadas a realizar cortes indesejáveis em prol da sobrevivência organizacional. Para além da forte redução na força de trabalho, sendo que 43\% das empresas reduziu o número de colaboradores, verificou-se que em 2013 já $40 \%$ das empresas haviam assumido o congelamento do salário base dos seus colaboradores. Durante o mesmo 
período de tempo a percentagem de empresas que efetuou cortes no salário base dos seus colaboradores aumentou em 2\%, ou seja, de 1.9\% em 2010 para 3.9\% em 2013. Além disso, o corte das componentes flexíveis da compensação dos trabalhadores sofreu um grande abalo tendo sido reduzidas ou extintas em $73 \%$ das empresas.

Apesar de escassa, a literatura sobre o impacto dos cortes ou redução das recompensas, quer sejam estas monetárias ou não, tem sido inequívoca ao demonstrar o seu impacto sobre a intenção de saída dos colaboradores, bem como da sua motivação para o desempenho (Bewley, 1998). Exemplo disto é o estudo experimental realizado por Kube e colaboradores (2013), os investigadores aproveitaram a necessidade real de realizar uma catalogação de livros numa das bibliotecas de uma Universidade Alemã para colocar um anúncio de recrutamento em que ofereciam um dia de trabalho (seis horas) remuneradas a $15 €$ por hora. Foram elaborados aleatoriamente dois grupos experimentais e um de controlo. Aos elementos de um dos grupos experimentais foi-lhes informado que iriam receber $10 €$ e não $15 €$ como anunciado, enquanto no segundo grupo experimental recebeu um aumento tendo-lhes sido dito que receberiam $20 €$ em vez de $15 €$. 0 grupo de controlo foi informado que iriam receber exatamente a quantia anunciada, $15 €$. Os resultados obtidos demonstraram uma diferença significativa na produtividade do grupo do corte salarial quando comparado com o grupo de controlo, existindo uma diminuição $21 \%$ na produtividade o que significa o registo de menos 47 livros por jornada. Além disso, entre o grupo de controlo e o grupo de aumento salarial não se verificaram diferenças significativas. No mesmo sentido vão os dados obtidos por Chen e Horton (2009), num estudo igualmente experimental, os autores verificaram que perante uma diminuição do pagamento acordado os colaboradores diminuíram significativamente o seu desempenho, tendo aumentado, também, a probabilidade de saída. Tal como no estudo anterior, também Chen e Horton (2009) não verificaram alterações quando existiram aumentos do pagamento.

A quebra do desempenho dos colaboradores e a sua intenção de saída voluntária em momentos de cortes de recompensas, acarretam consequências extremamente graves para as empresas (Huselid, 1995).E, contrariamente ao que intuitivamente se poderia esperar, apesar do aumento das taxas de desemprego durante a crise económico financeira, parecem existir evidências de que os colaboradores continuam a sair voluntariamente da organização mesmo perante um contexto externo adverso. Primeiramente podemos observar estes dados pelo relatório intitulado "Impact of the crisis on working conditions in Europe" apresentado em 2013 pela European Foundation For Improvement of Living and Working Conditions (EuroFound, 2013a) que analisa em números o impacto da crise no mercado e nas condições de trabalho. De acordo com esta entidade Europeia, os movimentos entre emprego-emprego, ou seja, a saída voluntária dos colaboradores de uma organização para outra sofreu um pequeno decréscimo nos primeiros anos de crise, tendo reagido e aumentado rapidamente aos primeiros sinais de melhoria económica. Isto significa que apesar da crise na sua fase inicial ter impacto sobre a saída voluntária dos colaboradores diminuindo-a, esse efeito é rapidamente anulado voltando a aumentar. Pelo que, as preocupações com a intenção de saída dos colaboradores não é de descurar apesar das elevadas taxas de desempego. Adicionalmente, Wyen e Beeck (2014) ressalvam que são os colaboradores mais talentosas e que se percecionam como possuindo uma maior empregabilidade tendem a procurar mais oportunidades externas perante os cortes na organização empregadora. Além disso, Meyer, Morin e Wasti (2018) verificaram que os valores de intenção de saída dos colaboradores aumentam significativamente no período pós-crise. Este facto pode condicionar a recuperação financeira das empresas durante o período de retoma. Quer a quebra de desempenho, quer a intenção de saída dos colaboradores mesmo em momentos adversos, podem ser explicados por exemplo pela teoria do contrato psicológico. Para Conway e Briner (2005) o contrato psicológico refere-se ao conjunto, implícito e explícito, de promessas envolvendo deveres e direitos entre empregador e empregados. Tal como acontece em outros momentos de crise organizacional (eg.: Downzising, Layoff) (Boswell, Olson-Buchanan \& Harris, 2014), os colaboradores poderão encarar o corte ou redução de recompensas como uma quebra desse contrato psicológico. Sem dúvida que os colaboradores percecionam o pacote de recompensas acordado como um os seus direitos nesta relação entre empregado-empregador logo, o seu corte ou redução, configura-se como uma violação deste contrato psicológico e das expectativas que lhes estão inerentes, produzindo inevitavelmente à perceção de desequilíbrio na relação de troca entre empregador-colaborador (Schreurs et al., 2011). Assim, o impacto negativo surge na tentativa de restaurar este equilíbrio, através da qual os colaboradores são motivados a reduzir o seu compromisso e a envolver-se em comportamentos de absentismo que contribuem para a baixa produtividade da organização (Jensen, Opland \& Ryan, 2010). De acordo com isto, para a diminuição do desempenho e a intenção de saída traduz-se numa tentativa dos colaboradores para a reduzir deliberadamente o seu investimento no trabalho de forma a reporem os níveis de equilíbrio ou justiça. Katou (2013) num estudo empírico com dados recolhidos na Grécia entre 2008 e 2010, país fortemente afetado pela crise financeira, verificaram que as alterações que são levadas a cabo pelas organizações em períodos de crise económica podem conduzir á alteração da natureza do 
contrato psicológico de trabalho e consequentemente conduzir a perceção do colaborador sobre a sua violação ou quebra desse contrato, enfraquecendo o vínculo da relação entre colaborador e empregador. Também neste sentido Wei, Ma, Zhang, Showail, Jiao e Wang (2015) concluíram que as diversas estratégias de redução de custos levadas a cabo pelas organizações em momentos de crise económica apresentam um impacto direto significativo na quebra do contrato psicológico de trabalho.

Além disto, a reação dos colaboradores aos cortes/reduções de recompensas também poderá ser vista através da teoria da Aversão à Perda de Kahneman e Tversky (1979). De acordo com esta teoria o comportamento do Ser Humano pauta-se mais pelo medo de perder do que pelo prazer de ganhar. Baseado, então, no conceito de aversão à perda pode-se verificar que o medo de perder poderá conduzir à tomada de decisões irracionais, uma vez que o medo cria uma moldura cognitiva que deixa os indivíduos "cegos" a fatos históricos e/ou probabilísticos. A teoria da aversão á perda diz-nos que os indivíduos não têm aversão ao risco como se pensava, mas sim há perda, optando, na maioria das vezes por evitar a dor da perda a sentir o prazer de ganhos equivalentes. Assim, por forma a evitar que as perdas ocorram, o ser humano é capaz de assumir riscos que a impossibilitem, contudo, quando estão a ganhar são avessos ao risco.

De acordo com esta teoria, em contextos de cortes ou reduções de recompensas tal como a apresentada no presente artigo, os colaboradores interpretam estas reduções ou cortes enquanto perdas efetivas. Esta sua aversão à perda irá conduzi-los a assumir riscos e a ignorar o contexto económicofinanceiro totalmente adverso e as elevadas taxas de desemprego, iniciando então uma procura de um novo emprego que lhes permita evitar a perda. Risco que não assumiriam neste contexto caso a perda/corte de recompensas não estivesse presente.

Contudo, tal como visto anteriormente, nem todas as pessoas trabalham pelas mesmas motivações principais (Rosso, Dekas \& Wrzesniewski, 2010) e, além disso, também nem todas as pessoas valorizam as recompensas da mesma forma (Vroom, 1964) e, como tal, nem todas as pessoas reagem da mesma forma aos cortes de recompensas aqui apresentados.

Assim, de seguida, será apresentado conceito de Orientação para o Trabalho, variável individual que surge no modelo proposto enquanto variável moderadora da relação entre cortes de recompensas e comportamento dos colaboradores.

\section{Orientação para o trabalho}

0 trabalho assume um papel central na vida da maioria das pessoas pelo que a escolha de uma atividade profissional não passa apenas pelas recompensas económicas, mas também pela gratificação e pelo significado pessoal e social que daí possa advir. Apesar do trabalho desempenhar um papel significativo na vida da maioria dos indivíduos, o significado psicológico que lhe é atribuído varia entre os indivíduos. E, neste sentido, a Orientação para o trabalho capta as diferentes variações dos significados que são atribuídos ao trabalho (Fossen \& Vredenbergh, 2014).

Este conceito trata, então, da vivência ou experiência subjetiva de trabalho, caracterizando os principais tipos de significados que as pessoas atribuem à sua atividade profissional, ou seja, diz respeito ao papel que a atividade profissional representa na vida global de um indivíduo (Rosso, Dekas \& Wrzesniewski, 2010).

A orientação para o trabalho ganhou maior relevância a partir do estudo de Wrzesniewski e colaboradores (1997) no qual os autores procuraram ampliar a compreensão sobre a experiência subjetiva do trabalho, tendo verificado a existência de 3 estilos ou tipos diferentes (Emprego, Carreira e Chamamento), que guiam os indivíduos para os seus objetivos centrais, compreendem as crenças dos indivíduos sobre o papel do trabalho na sua vida e refletem os seus sentimentos e comportamentos no que ao contexto organizacional diz respeito (Wrzesniewski, 2003).

As pessoas que percecionam o seu trabalho como um Emprego procuram retirar deste apenas benefícios materiais, não encarando o trabalho como um fim em si mesmo, mas sim como um meio ou instrumento para aquisição de recursos financeiros que lhe permitam disfrutar do seu tempo de lazer (Wrzesniewski et al., 1997), o que inclui hobbies e outros interesses e atividades (Rosso et al., 2010).

Por sua vez, as pessoas que percecionam o seu trabalho ou vida profissional enquanto Carreira, envolvem-se, não apenas, nem principalmente, por questões monetárias, mas acima de tudo pelo seu interesse de ascensão na carreira, associada, por muitas vezes, à procura de reconhecimento e poder, motivações relacionadas com um maior status social e profissional, bem como a uma maior autoestima (Wrzesniewski et al., 1997). Esta orientação é sobretudo marcada por um misto de motivações internas e externas.

Contudo, no que se refere ao chamamento, a intensa investigação sobre o tema tem conduzido a múltiplas tentativas de definição do conceito, o que tem resultado na atual proliferação de definições do constructo na literatura, que na sua essência, divergem, sobretudo, no que respeita às fontes, ou seja, à origem deste (Duffy \& Dik, 2013). Assim, podemos observar na literatura, a definição mais clássica, que 
define o chamamento como tendo um caracter religioso, considerando-o como um chamamento divino (Davidson e Caddell, 1994) ou como uma intimação divina para o exercício de dada carreira (Dalton, 2001). A segunda perspetiva tem sido definida por neoclássica e, desapegou-se da orientação religiosa passando a estar mais enfatizado o sentido de destino e/ou dever pró-social, possuindo uma significância mais social que pessoal (e.g.: Bunderson e Thompson, 2009). Passando a ter um foco cada vez mais interno e ligado à satisfação ou realização do Eu, a perspetiva moderna foca a existência de forças internas impulsionadoras como a autorrealização ou a felicidade pessoal (Duffy \& Dik, 2013). Um exemplo desta perspetiva é a definição de Dobrow (2004), onde o autor descreveu o chamamento como uma escolha de carreira motivada pela paixão pessoal e propõe que é um constructo constituído por 7 elementos: paixão, no sentido de profundo prazer e satisfação em se envolver em dada atividade; identidade, na medida em que existe uma congruência total entre o eu pessoal e o eu profissional; urgência, representando a necessidade urgente de envolvimento na atividade; longevidade, sentimento de certeza que o trabalho o acompanhará sempre; consciência, no sentido em que se trata de uma prática deliberada da qual o individuo disfruta conscientemente; trabalho significativo, na medida em que é percebido como intrinsecamente gratificante e, por fim, autoestima, os indivíduos com chamamento têm a sua autoestima claramente associada ao seu desempenho laboral.

Assim, as investigações que relacionam a orientação para o trabalho com outras variáveis do comportamento organizacional, focam essencialmente o chamamento (Duffy \& Dik, 2013), e têm associado o chamamento a melhores níveis de saúda física e psicológica, menor absentismo, bem como melhores performances, maior nível de autoestima e status social e, ainda, atingiam melhores níveis de remuneração e de carreira. Além disso, ver o trabalho como um chamamento está fortemente relacionado com o comprometimento organizacional, esta relação é fortemente explicada pelo comprometimento com a carreira/função (Duffy, Dik \& Steger, 2011).

Contudo, é escassa a investigação que analise a orientação para o trabalho em contextos adversos como o que serve de base ao presente estudo. Porém, dois estudos mais recentes contribuem com informação relevante sobre o comportamento de indivíduos com orientação Chamamento. Por exemplo, Esteves e Lopes (2016) realizaram um estudo com profissionais da área da saúde verificando que o aumento do desafio percebido aumenta o sentido de chamamento. Além disso, o sentido de chamamento, enquanto variável mediadora, medeia totalmente a relação positiva entre o aumento de desafio e a intenção de saída dos profissionais. Num estudo sobre as estratégias de coping em pessoas desempregadas, Duffy e colaboradores (2015) verificaram que os indivíduos desempregados, cuja sua orientação para o trabalho é o chamamento recorrem mais frequentemente a estratégias de confronto ou enfrentamento positivas quando comparados com indivíduos desempregados que demonstrem outro tipo de orientação, além disso, estes indivíduos demonstraram também uma visão mais otimista sobre a sua situação.

Em suma, tendo em conta que diferentes estilos de orientação para o trabalho refletem os diferentes significados atribuídos à atividade profissional, determinando diferenças individuais na relação que cada colaborador estabelece com o trabalho, principalmente naquilo que o motiva para a atividade laboral. Isto explica algumas disparidades ao nível dos comportamentos dos indivíduos em contexto organizacional (Pitacho \& Palma, 2015), a secção seguinte irá teorizar a respeito de como esta diferença individual explica diferentes comportamentos perante cortes ou reduções em distintos componentes do sistema de recompensas.

\section{PROPOSTA DE MODELO CONCEPTUAL}

0 atual artigo apresenta um modelo conceptual que teoriza a respeito do modo como a orientação para o trabalho de cada colaborador irá moderar a relação existente entre o corte ou redução de recompensas e o seu comportamento. Este modelo vai ao encontro dos autores que apelam à necessidade de procurar variáveis moderadores que ajudem a clarificar a relação entre as recompensas e as atitudes e comportamentos dos colaboradores (eg.: Young, Beckman \& Baker, 2012), no sentido de compreender o seu verdadeiro impacto. E ainda, tem em linha de conta alguns investigadores (eg.: Cardador, 2008; Fossen \& Vredenberg, 2014) que consideram a orientação para o trabalho como uma variável individual que poderá constituir-se como um fator relevante para a compreensão da variabilidade do comportamento organizacional. Para o efeito, para além dos três estilos de orientação para o trabalho serão contempladas recompensas de diferentes naturezas, nomeadamente, salário base, bónus e benefícios monetários/ não monetários, oportunidade de promoção/carreira e, oportunidade de desenvolvimento e formação. A escolha pelas recompensas supracitadas prende-se com o facto de corresponderem a recompensas de diferentes naturezas e por outro lado aos cortes e reduções levadas a cabo por empresas e governos durante o período de grande recessão (Fabiani et al., 2015).

Focando, então, a orientação de emprego verifica-se que os colaboradores com esta orientação estabelecem uma relação transacional com o seu trabalho, onde os trabalhadores se limitam a efetuar as 
suas tarefas mínimas requeridas, esperando por parte da entidade empregadora apenas o salário (Palma \& Lopes, 2012). Neste sentido, para os colaboradores de orientação de emprego o trabalho tem um valor meramente instrumental que lhes dá acesso a recursos financeiros que lhes permite aceder a bens e atividades extralaborais, que no fundo se constituem como a sua real fonte de prazer e satisfação (Wrzesniewski et al., 1997).

Assim, tendo em conta que estes colaboradores não estão dispostos a sacrifícios em prol do seu trabalho ou da sua carreira então, não ambicionam atingir bónus, benefícios ou até mesmo promoções que impliquem um maior envolvimento e dedicação com a sua atividade laboral. E, focando o conjunto de recompensas a analisar, o comportamento dos colaboradores com orientação de emprego será afetado apenas pela redução do salário base, uma vez que este compromete a sua motivação base para o trabalho. Logo, à luz da teoria do contrato psicológico de trabalho, por exemplo, este corte no salário base constitui uma violação clara deste contrato psicológico e, portanto, de forma a estabelecer um novo equilíbrio da relação será de esperar que os colaboradores diminuam o seu desempenho (Conway \& Briner, 2005). Adicionalmente, de acordo com Katou (2013) os colaboradores, em momentos de crise económica, contrariamente aos períodos de normalidade, prestam mais atenção às promessas transacionais imediatas do que as promessas relacionais a longo-termo e, como tal, a quebra das primeiras teria um maior impacto ao nível do contrato psicológico de trabalho. Além disso, será igualmente expectável que os colaboradores com orientação de empregam assumam o risco de procura de uma nova entidade empregadora, uma vez que já estão em situação da perda, tal como preconizado pela teoria de aversão à perda de Kahneman e Tversky (1979).

Desta forma, pode-se então afirmar que enquanto variável moderadora, a orientação de emprego surge como uma variável individual amplificadora da reação negativa dos colaboradores ao corte do salário base, no que respeita ao seu desempenho e intenção de saída, ou seja:

Proposição 1A: Numa situação de redução do salário base, os colaboradores com orientação de emprego irão aumentar a sua intenção de saída.

Proposição 1B: Numa situação de redução do salário base, os colaboradores com orientação de emprego irão diminuir o seu desempenho.

Atendendo, por sua vez, a orientação de carreira, verifica-se que estes colaboradores trabalham essencialmente motivados pela ascensão de carreira, mas também pela ambição de reconhecimento e status, quer profissional quer social (Wrzesniewski, 2003). Além disso, apesar de não existir uma ligação direta entre as motivações subjacentes à orientação de carreira e os bens materiais que resultam da atividade laboral, o dinheiro, tal como é referido por Hakonen e colaboradores (2011) está associada a valores emocionais e simbólicos relacionados ao status social e autoestima. Este facto significa que se por um lado a redução do salário base poderá não ter grande significado para as ambições dos colaboradores com orientação de carreira, o mesmo não acontece no que se refere aos bónus e benefícios monetários e não monetários. Ao se verificarem cortes ao nível deste bónus e benefícios significaria que estes colaboradores irão deixar de ostentar determinados bens que até à data lhe conferiam o status tão ambicionado, como por exemplo, os carros, telecomunicações, etc. Além disso, o seu mérito deixa de ser reconhecido através de bónus ou prémios que muito para além do seu valor financeiro ou monetário, não centrais na orientação de carreira são vistos como símbolos de reconhecimento, de poder e status. Tendo em linha de conta que a redução ou corte de bónus e benefícios se encontram dentro das expectativas dos colaboradores enquanto um dever da entidade empregadora ou dentro do "pacote" de promessas transacionais desta, podemos considerar que este afeta a ligação que os colaboradores mantêm com a organização por via da quebra do contrato psicológico de trabalho. E, portanto, tal com o acontece com os colaboradores com orientação de emprego em momentos de corte salarial, os colaboradores com orientação de carreira interpretam o corte ou redução de bónus e benefícios como uma perda real. Neste sentido, e de acordo com o preconizado pela teoria da aversão à perda (Kahneman e Tversky, 1979), perante este cenário e de forma a evitar a perda, os colaboradores assumem o risco de procura de trabalho fora da organização, mesmo existindo um contexto completamente adverso tendo em conta as elevadas taxas de desemprego durante a crise económica e financeira. Contudo, atendendo a que o objetivo central dos colaboradores com orientação de carreira se prende com a ambição de ascensão de carreira, tal como o próprio nome indica (Wrzesniewski, 2003), estes colaboradores não deixarão que o seu desempenho seja afetado enquanto permanecerem na organização, tanto pela imagem que querem projetar como pelas oportunidades que a crise lhes poderá proporcionar dentro da organização. Ou seja, de forma consistente com outros estudos, em tempos de crise económica, os colaboradores procuram aumentar a sua empregabilidade no mercado externo de trabalho, mas concomitantemente, procura também melhores oportunidades na organização atual (Katou, 2013). Assim, verifica-se que a orientação de carreira enquanto 
variável moderadora amplifica o impacto negativo do corte ou redução de bónus e benéficos na intenção de saída dos colaboradores, mas, atenua o seu impacto no desempenho dos mesmos. Ou seja:

Proposição 2A: Numa situação de corte ou redução de bónus e benefícios os colaboradores com orientação de carreira aumentam a sua intenção de saída.

Proposição 2B: Numa situação de corte ou redução de bónus e benefícios os colaboradores com orientação de carreira mantêm os seus níveis de desempenho.

Ainda no que respeita à orientação de carreira, estes colaboradores são ainda influenciados pelo corte de oportunidades de promoção/carreira, bem como pelo corte das oportunidades de desenvolvimento e formação. O corte destas recompensas afeta diretamente os colaboradores que ambicionam a ascensão na carreira, uma vez que colide de forma inevitável com essa ambição. Desta forma, sendo que os colaboradores com orientação de carreira procuram inequivocamente a sua ascensão (Wrzesniewski et al., 1997), ao deixarem de existir oportunidades de promoção, logo de ascensão na carreira, então, estes perdem a sua motivação quer para o desempenho, quer para permanecerem numa organização que não lhes irá proporcionar aquilo que desejam, sendo por isso, expectável que estes diminuam o seu desempenho, em prol da reposição do equilíbrio da relação tal como preconizado pelo rompimento do contrato psicológico de trabalho (Conway \& Briner, 2005). Além disso, aumentam a sua intenção de saída, pois tal como visto anteriormente, apesar do contexto socioeconómico adverso, estes colaboradores irão evitar a perda (Kahneman e Tversky, 1979), aqui exposta pela perda de oportunidades de evolução de carreira.

0 mesmo acontece perante o corte das oportunidades de desenvolvimento e formação na medida em que se constituem como entrave à sua evolução e desenvolvimento de competências, o que de forma evidente representa uma estagnação que claramente se opõe à sua ambição de ascensão de carreira e ao aumento da empregabilidade, logo, mais uma vez, tendo em conta que este corte representa uma perda real para o seu objetivo central, os colaboradores com orientação de carreira irão reagir de forma negativa a estes cortes, tando no que respeita à sua intenção de saída como no que concerne ao seu desempenho.

Em suma, a orientação de carreira enquanto variável moderadora amplifica o impacto negativo do corte de oportunidades de promoção, de desenvolvimento e formação na intenção de saída dos colaboradores e também, no seu desempenho:

Proposição 2C: Numa situação de corte de oportunidades de promoção, desenvolvimento e formação os colaboradores com orientação de carreira aumentam a sua intenção de saída.

Proposição 2D: Numa situação de corte de oportunidades de promoção, desenvolvimento e formação os colaboradores com orientação de carreira diminuem os seus níveis de desempenho.

Importa, agora, atender aos colaboradores com orientação de chamamento. As pessoas com chamamento, quase por oposição à orientação de emprego, demonstram uma motivação interna para o exercício laboral, o que reflete uma paixão pessoal (Dobrow, 2004) e, de acordo com Bunderson e Thompson (2009) cria nos indivíduos uma predisposição para a realização de sacrifícios a diversos níveis, incluindo monetários e de carreira. Neste sentido, ao não focar as questões financeiras como prioritárias e estando a suas motivações associadas à autorrealização e/ou transcendência, contrariamente ao que acontece com os colaboradores com orientação de Emprego (Wrzesniewski, 2003). Além disso, também se afastam dos colaboradores com orientação de carreira, uma vez que não são movidos por motivações associadas à evolução de carreira, uma vez que sentem a sua função como uma missão de vida pró-social (Wrzesniewski et al., 1997). Sendo expectável que o seu contrato psicológico de trabalho assente sobretudo nas promessas relacionais de longo prazo e não das promessas transacionais. Posto isto, perante reduções do salário base ou reduções de bónus e benefícios, bem como, de oportunidades de promoção a orientação de chamamento irá surgir como um fator moderador atenuante, uma vez que a sua real motivação é intrínseca e livre de ambições de carreira:

Proposição 3A: Numa situação de redução do salário base ou redução de bónus e benefícios e de oportunidades de promoção os colaboradores com orientação de chamamento não aumentam a intenção de saída.

Proposição 3B: Numa situação de redução do salário base ou redução de bónus e benefícios e de oportunidades de promoção os colaboradores com orientação de chamamento mantêm os seus níveis de desempenho.

Contudo, o mesmo não acontece com o corte das oportunidades de desenvolvimento e formação uma vez que para os colaboradores com orientação de chamamento é importante a aquisição de novos conhecimentos e competências que lhe permitam executar cada vez melhor as suas tarefas e, portanto, missão de vida. Posto isto, este corte representa um obstáculo ao seu objetivo e terá uma influência negativa 
sobre a sua intenção de saída, procurando, os colaboradores uma outra organização onde lhe seja permitido levar a cabo a sua função em melhores condições. Contudo, no que respeita ao desempenho, a orientação de chamamento mantém-se como um fator moderador atenuante, uma vez que estes colaboradores não deixarão o seu desempenho ser afetado em prejuízo da sua missão uma vez que para si o trabalho é gratificante em si mesmo (Wrzesniewski et al., 1997).

Proposição 3C: Numa situação de corte das oportunidades de desenvolvimento e formação os colaboradores com orientação de chamamento aumentam a intenção de saída.

Proposição 3D: Numa situação de corte das oportunidades de desenvolvimento e formação os colaboradores com orientação de chamamento mantêm os seus níveis de desempenho.

No que respeita à orientação de chamamento e ao corte das recompensas monetárias existe uma ressalva. A orientação de chamamento será uma atenuante no impacto negativo do corte destas recompensas apenas quando o mesmo não colocar em causa as suas necessidades de subsistência e qualidade vida dos colaboradores. De acordo com diversas teorias da motivação, destacando-se a teoria clássica de Herzberg (1959) a recompensa financeira ou o salário de um colaborador não é um fator motivador, mas é um fator necessário à motivação dos colaboradores ou neste caso um fator higiénico.

Posto isto podemos considerar que a orientação para o trabalho determina diferentes relações com o trabalho e, principalmente com aquilo que cada indivíduo espera da sua atividade laboral, explicando diferenças individuais nas preferências sobre recompensas e, principalmente nas reações aos cortes dessas recompensas, logo, de uma forma genérica:

Proposição 4: Numa situação de corte ou redução de recompensas a orientação para o trabalho surge como uma variável moderadora entre estes cortes e a intenção de saída e desempenho dos colaboradores.

\section{IMPLICAÇõES E CONCLUSÕES}

Em linha com a literatura científica que apela à necessidade de variáveis que apoiem na compreensão do impacto das recompensas no comportamento dos colaboradores (eg.: Young et al., 2012), o presente artigo concetualiza um modelo que coloca a orientação para o trabalho como uma variável individual explicativa da variabilidade do comportamento dos colaboradores perante o corte de diferentes recompensas, cumprindo assim o seu principal objetivo.

As proposições teóricas apresentadas partem do pressuposto empiricamente validado pela literatura de que as recompensas têm impacto no comportamento dos colaboradores, nomeadamente sobre o seu desempenho e intenção de saída (eg.: De Gieter \& Hofmans, 2015; Rynes et al., 2004). Além disso, apesar de escassos, os estudos realizados em momentos de crise económica e financeira, bem como os estudos que retratam os cortes salariais, têm sido unânimes a demonstrar que o contexto não muda a direção desta relação e que apesar das adversidades os cortes continuam a estar associados a quebras de desempenho e ao aumento da intenção de saída dos colaboradores (eg.: Chen \& Horton, 2009; Kube et al., 2013). Pelo que, pela primeira vez, este estudo apresenta a orientação para o trabalho como uma variável moderadora entre esses cortes e os comportamentos dos colaboradores. Evidenciando que, em função da sua orientação para o trabalho o comportamento dos colaboradores será diferenciado perante os diferentes cortes.

No que concerne às implicações para a literatura das recompensas contribui com um novo fator moderador, a orientação para o trabalho, que explica não só as diferentes reações ao corte ou redução de recompensas, mas para a relação entre os sistemas de recompensas e o comportamento dos colaboradores de um modo geral. Adicionalmente reflete e ilustra como cada tipo de recompensa motiva de forma diferenciada os colaboradores com diferentes tipos de orientação para o trabalho. Apoiando, assim a compreensão da variabilidade do impacto positivo ou negativo dos incentivos financeiros no desempenho e na retenção dos colaboradores. De forma mais modesta, contribui, ainda, com um importante fator moderador para a compreensão da intenção de saída e da sua relação não linear com a satisfação com o pagamento. Contribuindo, também, para explicar as razões pelas quais apesar dos colaboradores percecionarem o mercado de trabalho como adverso continuarem a aumentar a sua intenção de saída perante determinados cortes na área das recompensas.

Ainda no que às implicações teóricas diz respeito o presente modelo concetual dá um contributo igualmente relevante para literatura da orientação para o trabalho e, consequentemente para uma maior compreensão do comportamento organizacional na medida em que não segue a linha de investigação tradicional que tende a pesquisar o chamamento como antecedente de outras variáveis individuais. Este modelo não se foca em exclusivo no chamamento, parte do modelo tripartido de orientação para o trabalho, analisando esta experiência subjetiva como variável moderadora. Reforçando, assim, o papel explicativo relevante que a orientação para o trabalho pode desempenhar nas teorias do comportamento organizacional, não só a nível micro, mas também a nível macro no que concerne ao desenho de políticas 
de recursos humanos, como por exemplo no que diz respeito ao sistema de recompensas. Posto isto, podese considerar este modelo inovador na medida em que coloca a orientação de trabalho como variável moderadora, por atender às três dimensões de orientação para o trabalho e não apenas ao chamamento e ainda, ao estabelecer uma relação entre a orientação para o trabalho e os sistemas de recompensas.

No que respeita à sua implicação prática para o campo das recompensas, toda a teorização na base do modelo apresentado aponta, tal como Vroom (1964), para o facto de poder ter mais impacto a interpretação que o colaborador faz da recompensa, ou da sua redução, do que o próprio acontecimento em si. Logo, apoia a importância dos sistemas globais de recompensas e, apela ainda para o facto de que sem se deixar de respeitar as teorias da equidade e justiça se concebam sistemas flexíveis que tenham em conta a individualidade e preferências subjacentes a cada orientação para o trabalho. Ou seja, o presente modelo e artigo pretende realçar as diferenças individuais como fatores extremamente relevantes para a tomada de decisão das organizações no que diz respeito a conceção dos seus sistemas de recompensas. Adicionalmente, importa esclarecer que este trabalho não tem como objetivo indicar uma orientação para o trabalho ideal dos colaboradores, mas sim alertar para o facto de que o significado psicológico que cada colaborador atribui ao seu trabalho tem impacto sobre o seu comportamento e como tal este é um facto que deverá ser tido em conta pela gestão principalmente em momentos de crise por forma a minimizar perdas relativas a colaboradores que possam comprometer a saúde organizacional no pós crise. Isto porque, tal como visto anteriormente, os trabalhadores que tendem a aumentar a sua intenção de saída, e até a concretizá-la são aqueles que percecionam ter uma maior empregabilidade, pelo que as organizações poderão perder colaboradores chave, possuidores de maiores níveis de competência.

Em suma, o presente artigo dá a conhecer um modelo teórico que contribuí quer para a literatura científica como para as práticas de gestão. Contribui para a ampliação do conhecimento sobre a orientação para o trabalho, enquanto fator individual relevante para a compreensão do comportamento organizacional e, em particular, como variável moderadora do impacto das recompensas sobre os comportamentos dos colaboradores. Além disso, do ponto de vista da praxis organizacional, contribui para uma gestão mais eficaz dos recursos humanos nas organizações, nomeadamente no que respeita à gestão das políticas e práticas de compensação e motivação. Devendo-se, então, assumir a Orientação para o Trabalho como uma peça-chave para a compreensão do comportamento organizacional, mas também, para a delineação estratégica da gestão de pessoas.

\section{REFERÊNCIAS}

Abdullah, A., Bilau, A. A., Enegbuma, W. I., Ajagbe, A. M., Ali, K. N., \& Bustani, S.A. (2012). Small and medium size construction firms job satisfaction and evaluation in Nigeria. International Journal of Science and Humanity, 2(1), 34-46. https://doi.org/10.7763/IJSSH.2012.V2.65

Armstrong, M. (2010). Armstrong's Handbook of Reward Management Practice: Improving Performance Through Reward. $3^{\underline{a}}$ ed. Kogan Page Limited.

Babecký, J., Caju, P., Kosma, T., Lawless, M., Messina, J., \& Rööm, T. (2009). The Margins of Labour Cost Adjustment: Survey Evidence from European Firms. ECB Working Paper Serious no 1106. European Central Bank: Frankfurt. https://www.econstor.eu/bitstream/10419/153540/1/ecbwp1106.pdf.

Bewley, T. (1998). Why Not Cut Pay. European Economic Review, 42, 459-490. https://doi.org/10.1016/S0014-2921(98)00002-6.

Boswell, W., Olson-Buchanan, J., \& Harris, T (2014). I cannot afford to have a life: employee adaptation to feelings of job insecurity. Personnel Psychology, 67, 887-915. https://doi.org/10.1111/peps.12061

Bunderson, J. \& Thompson, J. (2009). The call of the wild: zookeepers, Calling, and the double-edged sword of deeply meaningful work. Administrative Science Quartely, 54, 32-57. https://doi.org/10.2189/asqu.2009.54.1.32

Cao, Z., Chen, J. \& Song, Y. (2013). Does total rewards reduce the core employees' Turnover Intention? International Journal of Business and Management, 8 (20), 62-75. https://doi.org/10.5539/ijbm.v8n20p62

Cardador, M. T. (2008). Re-orienting the career orientation: Implications for hybrid work orientations. Paper presented at the annual meeting of the Academy of Management, Anaheim, CA.

Carneiro. A., Portugal, P., \& Varejão, J. (2014). Catastrophic job Destruction during the Portuguese Economic Crisis. Journal of Macroeconomics, 39, 444-457. https://doi.org/10.1016/j.jmacro.2013.09.018

Chang, W., Wang, Y. \& Huang, T.(2013). Work design-related antecedents of turnover intention: A multilevel approach. Human Resource Management, 52 (1), 1-26. https://doi.org/10.1002/hrm.21515

Chen, D. \& Horton, J (2009). The Wages of Pay Cuts: Evidence from a Field Experiment. Social Science Research Network. https://doi.org/10.2139/ssrn.1443526 
Condly, S., Clark, R. \& Stolovitch, H. (2003). The Effects of Incentives on Workplace Performance: A Metaanalytic Review of Research Studies. Performance Improvement Quarterly, 16 (3), 7-24. https://doi.org/10.1111/j.1937-8327.2003.tb00287.x

Conway, N. \& Briner, R. (2005). Understanding Psychological Contracts at Work: A Critical Evaluation of Theory and Research. Oxford University Press.

Dalton, J.C. (2001). Career and Calling: finding a place for spirit in work and community. New Direction for Students Service, 95, 17-25. https://doi.org/10.1002/ss.19.

Davidson, J. C., \& Caddell, D. P. (1994). Religion and the meaning of work. Journal of the Scientific Study of Religion, 33, 135-147. https://doi.org/10.2307/1386600

De Gieter, S. and Hofmans, J. (2015) How reward satisfaction affects employees turnover intentions and performance: an individual differences approach. Human Resource Management Journal, 25 (2), 200-216. https://doi.org/10.1111/1748-8583.12072

Dhanpat, N., Nodau, F., Lugisani, P., Mabojane, R., \& Phiri, M. (2018). Exploring Employee retention and intention to leave within a call centre. SA Journal of Human Resource Management, 16 (0), 1-13. https://doi.org/10.4102/sajhrm.v16i0.905

Dobrow, S. (2004). Extreme subjective career success: a new integrated view of having Calling. Academy of Management Proceeding, B1-B6. https://doi.org/10.5465/AMBPP.2004.13863838

Duffy, R,. Dik, B., \& Steger, M. (2011). Calling and work related outcomes: career commitment as a mediator. Journal of Vocational Behavior, 78, 210-218. https://doi.org/10.1016/j.jvb.2010.09.013

Duffy, R. \& Dik, B. (2013). Research on Calling: What have we learned and where are we going? Journal of Vocational Behavior, 83, 428-436. https://doi.org/10.1016/j.jvb.2013.06.006

Duffy, R. D., Bott, E. B., Allan, B. A., \& Autin, K. A. (2015). Calling among the unemployed: Examining prevalence and links to coping with job loss. The Journal of Positive Psychology, 10 (4), 332-345. https://doi.org/10.1080/17439760.2014.967798

Elsby, M., Hobjin, B., \& Sahin, A., (2010). The Labor Market in Great Recession. Brookings Papers on $\begin{array}{llll}\text { Economic Activity, } & \text { Spring } & 2010 .\end{array}$ http://www.frbsf.org/publications/economics/papers/2011/wp11-29bk.pdf

Esteves, T. \& Lopes, M.P. (2016). Crafting a Calling: The Mediating Role of Calling Between Challenging Job Demands and Turnover Intention. Journal of Career Development. https://doi.org/10.1177/0894845316633789

Eurofound (2013a). Impact of the crisis on working conditions in Europe. Retriever from https://www.eurofound.europa.eu/publications/reports/2013/impact-of-the-crisis-on-workingconditions-in-europe

Eurofound (2013b). Wages and working conditions in the crisis. https://www.eurofound.europa.eu/publications/report/2013/wages-and-working-conditions-inthe-crisis

Fabiani, S., Lamo, A., Messino, J., \& Room, T. (2015). European Firm Adjustment During Times of Economic Crisis. European Central Bank, Working Paper Serious no 1778. https://www.ecb.europa.eu/pub/pdf/scpwps/ecbwp1778.en.pdf

Fossen, R.S., \& Vredenburg, D. (2011). Exploring Differences in Work's Meaning: An Investigation of Individual Attributes Associated with Work Orientations. Journal of Behavioral and Applied Management, 15 (2), 101-121.

Guest, D. (2017) Human resource management and employee well-being: towards a new analytic framework: HRM and employee well-being: new analytic framework. Human Resource Management Journal, 27(1), 22-38.

Hakonen, A., Maaniemi, J., \& Hakanen, J., (2011). Why is group-based pay perceived as meaningful, meaningless or negative? Exploring the meanings of pay suggest by reflection theory. The International Journal of Human Resource Management, 22 (10), 2245-2264. https://doi.org/10.1080/09585192.2011.580194

Herzberg, F. (1959). The motivation to work (2nd. Ed). John Wiley.

Huselid, M. (1995). The Impact of Human Resources Management Practices on Turnover, Productivity, and Corporate Financial Performance. Academy of Management Journal, 38 (3), 635- 872. https://doi.org/10.5465/256718

Jensen, J., Opland, R., \& Ryan, A. (2010). Psychological Contracts and Counterproductive Work Behaviors: Employee Responses to Transactional and Relational Breach. Journal of Business and Psychology, 25 (4), 555-568. https://doi.org/10.1007/s10869-009-9148-7

Kahneman, D., \& Tversky, A. (1979). Prospect Theory: An Analysis of Decision Under Risk. Econometrica, 47 (2), 263-291. 
Kanfer, R. \& Ackerman, P. L. (1989). Motivation and cognitive abilities: an integrative/aptitude-treatment interaction approach to skill acquisition. Journal of Applied Psychology, 74, 657-690. https://doi.org/10.1037/0021-9010.74.4.657

Katou, A.A. (2013). Justice, trust and employee reactions: An empirical examination of the HRM system. Management Research Review, 36 (7), 674-699. https://doi.org/10.1108/MRR-07-2012-0160

Kaya, C. \& Başkaya, R. (2016). The Roles of Organizational and Ethical Climate on Individual Performance of Employees. Business Management Dynamics, 5, (8), 27-38. http://search.ebscohost.com/login.aspx?direct=true\&AuthType=ip\&db=bth \&AN=123990550\&site=eds-live Martins, F. (2016). How the Portuguese firms Adjusted Between 2010 And 2013 Main Shocks And Channels Of Adjustment. Lisboa, Departamento de Estudos Económicos do Banco de Portugal. https://www.bportugal.pt/sites/default/files/anexos/papers/re201603_e.pdf.

Kube, S., Maréchal,M., \& Puppe, C.(2013) Do wage cuts damage work morale? Evidence from a natural field experiment. Journal of the European Economic Association, 11 (4), 853-870. https://doi.org/10.1111/jeea.12022

Meyer, J., Morin, A. \& Wasti, S.A. (2018). Employee commitment before and after an economic crisis: A stringent test of profile similarity. Human Relations, 71 (9), 1204-1233. https://doi.org/10.1177/0018726717739097

Palma, P. J. \& Lopes, M.P. (2012). Paixão e Talento no Trabalho. Edições Sílabo.

Peiró, J., Bayona, J., Caballer, A., \& Fabio, A. (2020). Importance of work characteristics affects job performance: The mediating role of individual dispositions on the work design-performance relationships. Personality and Individual Differences, 157. https://doi.org/10.1016/j.paid.2019.109808

Pitacho, L., \& Palma, P.J. (2015). Como Implementar Sistemas de Recompensas com Real Impacto na Produtividade. RH Magazine,96, 24-29.

Rosso, B.D., Dekas, K.H., \& Wrzesniewski, A. (2010). On the meaning of work: a theoretical integration and review. Research in Organizational Behavior, 30, 91-127. https://doi.org/10.1016/j.riob.2010.09.001

Rynes, S. L., Gerhart, B., \& Minette, K. A. (2004). The importance of pay in employee motivation: Discrepancies between what people say and what they do. Human Resource Management, 43, 381394. https://doi.org/10.1002/hrm.20031

Schmidt, J., Willness, C., Jones, D. \& Bourdage, J. (2018) Human resource management practices and voluntary turnover: a study of internal workforce and external labor market contingencies. The International Journal of Human Resource Management, 29 (3), 571-594. https://doi.org/10.1080/09585192.2016.1165275

Schreurs, B., Guenter, H., Schumacher, D., Emmerik, IJ. \& Notelaers, G. (2013). Pay-level satisfaction and employee outcomes: the moderating effect of employee-involvement climate. Human Resource Management, 52 (3), 399-421. https://doi.org/10.1002/hrm.21533

Syndicate European Trade Union (2014). Benchmarking Working Europe. http://www.etui.org/Publications2/Books/Benchmarking-Working-Europe-2014.

Tett, R.P., \& Meyer, J.P. (1993). Job satisfaction, organizational commitment, turnover intention, and turnover: Path analyses based on meta-analytic findings. Personnel Psychology, 46, 259-293. https://doi.org/10.1111/j.1744-6570.1993.tb00874.x

Vroom, V.H. (1964). Work and Motivation. John Wiley.

Wang, Q., Jiang, Y., Weng, Q., \& Wang, Q. (2019). A meta-analysis of the relationship between occupational commitment and job performance. Social Behavior and Personality: An international journal, 47 (8), 1-15. https://doi.org/10.2224/sbp.8232

Watson Jr. BW. \& Singh G (2005). Global pay systems: compensation in support of a multinational strategy. Compensation and Benefits Review, 37(1): 33-36. https://doi.org/10.1177\%2F0886368704273100

Wei, X., Ma, L., Zhang, Z-X., Showail, S., Jiao, J. \& Wang, X. (2015). Understanding psychological contract breach due to labour costs reduction: Contingent upon employee sex and managerial control.Journal of Occupational and Organizational Psychology, 88, 679-701. 1-16. https://doi.org/10.1111/joop.12092

Williams, M., Brower, H., Ford, L., Williams, L., \& Carraher, S. (2008). A comprehensive mode and measure of compensation satisfaction. Journal of Occupational and Organizational Psychology, 81, 639-668. https://doi.org/10.1348/096317907X248851

Wrzesniewski, A., (2003). Finding positive meaning at work. In K. Cameron et al. (eds), Positive Organizational Shcolarship (pp. 296-308). Berrett-koehler. 
Wrzesniewski, A., McCauley, C., Rozin, P. \& Schwartz, B. (1997). Jobs, Career, and Calling: People's Relations to Their Work. Journal of Research in Personality, 31, 21-33. https://doi.org/10.1006/jrpe.1997.2162

Wynen, J. \& Beeck, S. (2014). The Impact of the Financial and Economic Crisis on Turnover Intention in the U.S. Federal Government. Public Personnal Management, 43 (4), 565-585. https://doi.org/10.1177/0091026014537043

Young, G. J., Beckman, H., \& Baker, E. (2012). Financial incentives, professional values and performance: A study of pay-for-performance in a professional organization. Journal of Organizational Behavior, 33, 964-983. https://doi.org/10.1002/job.1770

\begin{tabular}{ll}
\multicolumn{2}{c}{ Historial do artigo } \\
Recebido & $03 / 2019$ \\
Aceite & $07 / 2020$ \\
Publicado & $08 / 2020$
\end{tabular}

